\title{
Processing sets of letters for order: Evidence from reaction time experiments
}

\author{
L. C. PERLMUTER \\ Virginia Polytechnic Institute and State University, Blacksburg, Virginia 24061 \\ and \\ BARRY L. LIVELY \\ Hutchings Psychiatric Center, Syracuse, New York 13210
}

\begin{abstract}
In two experiments, subjects were required to impose different levels of organization on randomly ordered letters. In a between-subject design, the subject was to identify the letter in the set coming first in the alphabet or to reorganize the set into an alphabetic sequence. In a within-subject design, presentation of the letters was followed by an instruction to carry out the identification or reorganization task or to recite the letters in left-to-right order. Reaction time varied systematically with level of required organization, size of the presented set, and position and spacing of the letter set in the alphabet. The results are discussed in terms of two simple models.
\end{abstract}

Efficient performance in many tasks requires that information be compared and organized according to some rule. An interpreter performing simultaneous translation at the United Nations and a librarian reshelving books each is applying rules for organization, although at manifestly different levels of difficulty. The interpreter's task is made difficult both by the complexity of the set of rules to be applied and the necessity for working under time pressure.

A simple class of organization problems amenable to experimental analysis can be generated by having the subject deal with a number of stimuli that can be ordered on a single dimension. Suppose, for example, the subject is given a randomly ordered set of letters. Different levels of organization or manipulation of the presented set can be imposed by requiring that the subject identify the letter in the presented set coming first in the alphabet (identification task) or report the members of the set in alphabetic sequence (reorganization task). Tasks of intermediate complexity requiring a partial ordering of the letter set could also be devised. The current report will, however. focus on the two tasks described. Both the amount of processing of the stimulus set and the number of responses to be spoken increase from the identification task to the reorganization task. That is, if the set GIFH were presented, the identification task

Experiment I was carried out while the authors were on the faculty of Bowdoin College and was reported at the meeting of the Psychonomic Society, St. Louis, 1972. The research was in part supported by Grant MH 15315 from NIMH to the first author. The technical assistance of Cecilia Cooney in this research is appreciated. Requests for reprints should be sent to Lawrence $C$. Perlmuter, Department of Psychology, Virginia Polytechnic Institute and State University, Blacksburg, Virginia 24061. would require only the location and identification of that letter in the set coming first in the alphabet $(F)$, while the reorganization task would call for a complete alphabetic ordering of the set with the further requirement that all the items be spoken in alphabetical order (FGHI).

Because the work described here is still in its early stages, the present report will concentrate on empirical relations among variables studied at the expense of theoretical development. However, a minimal framework for studying identification and reorganization tasks is provided by a simple stimulus processing model, which says that the subject generates a response or an ordering of responses by making pairwise comparisons among stimuli. Thus, if the subject is required to identify the letter coming first in the alphabet in a randomly ordered set of three letters (identification task), two pairwise comparisons would be needed to determine which letter was "least" on the alphabetic dimension. Similarly, if five letters were presented, four pairwise comparisons would be needed. If the task required a complete reordering of the set of five letters (reorganization task), many more comparisons would be necessary. This view of stimulus processing suggests a number of variables of potential importance. Two principal classes of variables will be considered here: those related to the difticulty of individual pairwise comparisons (stimulus discriminability variables) and those which manipulate the number of comparisons required.

A considerable body of psychophysical data (Woodworth \& Schlosberg, 1954) shows that the closer (or more similar) two stimuli are on some physical dimension, the longer it takes and the more error-prone subjects are in making a judgment of 
relative magnitude on the dimension. Similar results have been obtained in a paradigm developed by Moyer and Landauer (1967) in which the subject was to judge which of two simultaneously presented unequal digits was larger, the dependent variable being reaction time (RT). This procedure represents a special case of the identification task described here. It was found that RT decreased as the numerical difference between the digits increased and that RT increased with the position of the digits in the number series. Moyer and Landauer suggested that, in the performance of the task, the subject constructs analogs of the presented stimuli and compares them to determine which is larger. Hence, the more "discriminable" two digits are, i.e., the greater the percentage difference between them in terms of the magnitude of the constructed analogs, the faster is RT. Others have replicated these results with digits and with letter pairs (Fairbank, 1969; Lovelace \& Snodgrass, 1971; Parkman, 1971).

The effect of number of required comparisons on RT is also well documented. For example, in a paradigm related to that described here, Sternberg (1966) required subjects to indicate whether a presented item was a member of a previously memorized set. As predicted by a model which required that the presented item be compared sequentially with each item in the memorized set. RT to set members and nonmembers increased linearly (and at the same rate) as number of items in the memorized set increased. It should also be noted that in line with the discriminability data discussed earlier, variation in the physical similarity between presented and memorized items has been shown to affect RT in such a memory-search task (Chase \& Calfee, 1969).

The present report describes two experiments. The first determines the effect of some variables thought to affect the difficulty and number of comparisons required under identification and reorganization instructions. The second experiment confirms and extends the results of the first study under a somewhat different range of experimental treatments.

\section{EXPERIMENT I}

Following the simple model outlined earlier, the number of comparisons was affected by manipulating the nature of the task (identification vs. reorganization) and the size of the presented set (two, three. four, or five letters). Variables presumed to affect difficulty of pairwise comparisons were intermember distance and target set. Intermember distance refers to the "distance" among items in the presented set in the alphabet. Sets were constructed from adjacent letters (BDAC), letters one apart in the alphabet (CGAE), and letters two apart in the alphabet (DJAG). Target set identifies the pool of letters which would be first in the alphabetic sequence; these pools came from the beginning (A, B. C. D, or E) or niddle of the alphabet $(K, L, M, N$, or $O)$. In view of Moyer and Landauer's (1967) findings that RT varied both with numerical distance between digits to be compared and position of the digits in the number series, it would be expected that RT would increase as intermember distance decreases and be faster for the target set comprising letters from the beginning of the alphabet than for letters in the middle of the alphabet.

\section{Method}

Subjects. The subjects were 24 students. two of whom were women fulfilling a requirement in an elementary psychology course at Bowdoin College. Half the subjects were tested in the identification task and half were tested in the reorganization task.

Apparatus and Procedure. The stimulus sets were typed in uppercase elite and displayed in the second field of a two-channel Gerbrands (Model T1G1G) tachistoscope. The first field contained a random array of dots. The subject was verbally warned of the beginning of the trial $1-4 \mathrm{sec}$ prior to the presentation of the stimulus set and, after responding, was informed of his RT. The stimulus set was displayed for 4 sec; its duration was controlled by a Hunter Decade Interval Timer (Model 100-B). Vocal RT was measured with a Gerbrands (Model 730) electronic voice key and Hunter Klockounter (Model 120A).

Twenty-four conditions resulted from the combination of 2 target sets (A-E or K-O) by 3 intermember distances (zero. one. or two letters intervening in the alphabet) by 4 sizes of presented set (two, three. four. or tive letters). Under each condition, five stimulus sets were developed, each having a different target item. (If $O$ is the target at Intermember Distance 2 and five letters are presented, there are too few letters in the alphabet to maintain equal alphabetic spacing. Therefore, all stimuli at Intermember Distance 2 and Set Size 5 actually had a space of one letter between the penultimate and final letter in the alphabetic sequence.) An extra nine stimulus sets (extraneous trials) were constructed which were each two to tive items in length but which violated the target set and intermember distance requirements. These were included to deter the subject from detecting the rules used to construct the other stimuli. Performance on these extraneous sets was not scored. The 129 trials were divided into three blocks. with each block containing approximately the same number of sets from each condition. Within each block, the order of presentation of the various sets was random. The first trial block was preceded by four practice trials, and all trial blocks commenced with four unscored trials constructed in the same way as the extraneous trials defined earlier. Three orders of trial blocks were used for different subjects. Brief rest periods were given between trial blocks. Subjects were assigned to conditions according to a predetermined random order.

The subjects were instructed to respond quickly and accurately. Subjects in the reorganization condition were told to output the set in alphabetical order, but were given no specitic instructions concerning the temporal grouping of responses on a trial (i.e.. whether to delay the first letter in the sequence until all were in the output order or to respond as individual letters were available) because there was no effective way available to monitor the form of the temporal grouping.

Since the reorganization condition required that the subject recite all the letters in the presented set in alphabetical order and the identification condition required that the subject recite only the letter from the presented set which appeared earliest in the 
alphabet, the dependent variable was RT to the production of the (first) letter in both conditions. The RT analyses included only trials on which the response was correct. To equate for opportunity for errors between conditions, only the first spoken letter was scored under the reorganization condition.

\section{Results}

The mean RT data for correct responses averaged over subjects are plotted as a function of the number of items in the presented set in Figure 1, with task (identification vs. reorganization) and target set as parameters. Separate analyses of variance (Butler, Kamlet, \& Monty, 1969) for the two tasks revealed a main effect of intermember distance for identification $[F(2,18)=4.497, p<.05]$ but not for reorganization $[\mathrm{F}(2,18)=2.855, \mathrm{p}>.05]$. In neither case did intermember distance interact with target set or number of items. The data were, therefore, averaged over intermember distance for presentation in Figure 1. The data, broken down according to each of the major conditions, including intermember distance, are given in Table 1 . In the preceding and all other analyses, order of trial blocks was included as a between-subject variable. Since it produced neither a main effect nor an interaction with any other variable, it will not be discussed further. The major features derived from a visual inspection of Figure 1 are supported by the result of an analysis of variance comparing performance in the two tasks as a function of number of items in the presented set, intermember distance, and target set. All reported Fs are signiticant at $p<.005$. Mean squares for each main effect are given at the bottom of Table 1 . As is evident in Figure 1, RT is longer under the reorganization task $[\mathrm{F}(1,18)=24.371]$. In addition, $\mathrm{RT}$ is seen to

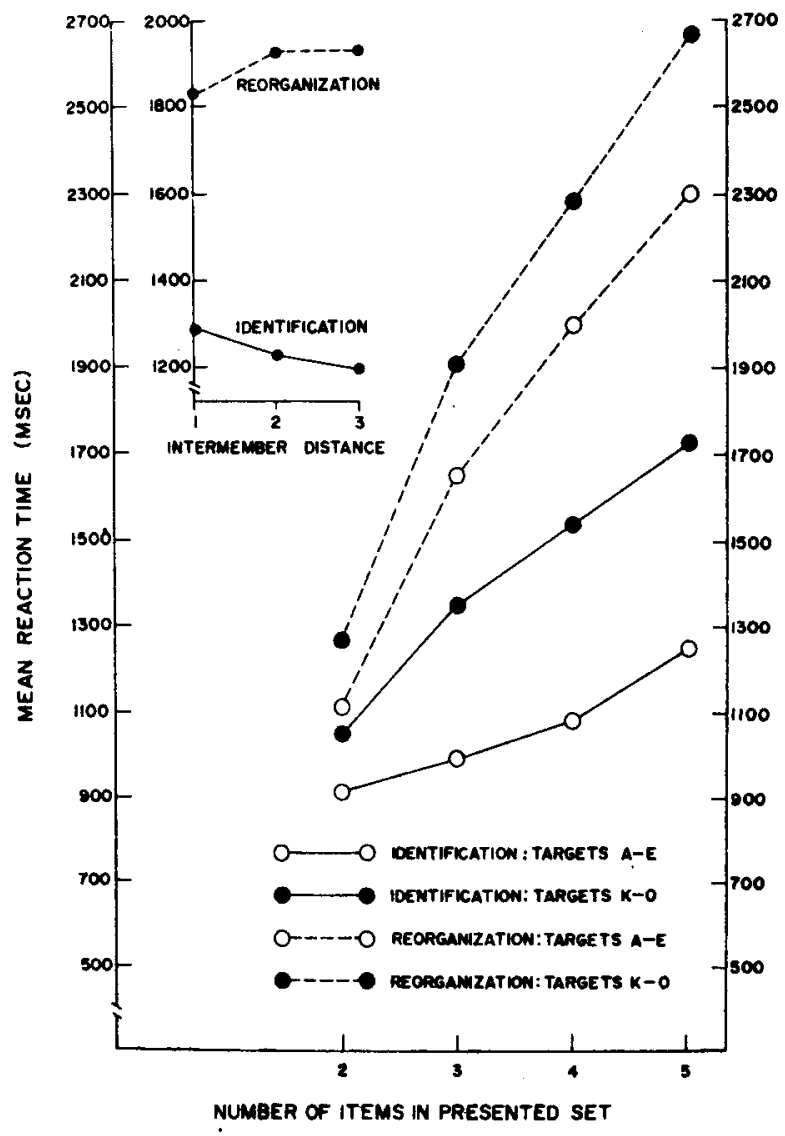

Figure 1. Mean RT as a function of set size with task requirements (identification vs. reorganization) and target set (A-E vs. $\mathrm{K}-\mathrm{O}$ ) as parameters. The inset displays mean $\mathrm{RT}$ as a function of intermember distance for the two tasks.

Table 1

Mean Correct RT (in Milliseconds) and Percentage Errors for the Various Conditions in Experiment I

\begin{tabular}{|c|c|c|c|c|c|c|c|c|c|c|}
\hline \multirow[b]{3}{*}{ Task } & \multirow[b]{3}{*}{$\begin{array}{l}\text { Target } \\
\text { Set }\end{array}$} & \multirow{3}{*}{$\begin{array}{c}\text { Inter- } \\
\text { member } \\
\text { Distance }\end{array}$} & \multicolumn{8}{|c|}{ Number of Items } \\
\hline & & & \multicolumn{2}{|c|}{2} & \multicolumn{2}{|c|}{3} & \multicolumn{2}{|c|}{4} & \multicolumn{2}{|c|}{5} \\
\hline & & & RT & $\begin{array}{l}\text { Percentage } \\
\text { Error }\end{array}$ & RT & $\begin{array}{l}\text { Percentage } \\
\text { Error }\end{array}$ & RT & $\begin{array}{l}\text { Percentage } \\
\text { Error }\end{array}$ & RT & $\begin{array}{c}\text { Percentage } \\
\text { Error }\end{array}$ \\
\hline \multicolumn{11}{|c|}{ Identification } \\
\hline & $A-E$ & $\begin{array}{l}1 \\
2 \\
3\end{array}$ & $\begin{array}{l}914 \\
939 \\
887\end{array}$ & $\begin{array}{r}18.3 \\
5.0 \\
5.0\end{array}$ & $\begin{array}{r}1035 \\
1034 \\
920\end{array}$ & $\begin{array}{r}20.0 \\
8.3 \\
10.0\end{array}$ & $\begin{array}{l}1134 \\
1053 \\
1052\end{array}$ & $\begin{array}{r}15.0 \\
11.7 \\
6.7\end{array}$ & $\begin{array}{l}1335 \\
1204 \\
1200\end{array}$ & $\begin{array}{l}18.3 \\
25.0 \\
20.0\end{array}$ \\
\hline & $\mathrm{K} \bullet \mathrm{O}$ & $\begin{array}{l}1 \\
2 \\
3\end{array}$ & $\begin{array}{r}1118 \\
996 \\
1045\end{array}$ & $\begin{array}{r}13.3 \\
13.3 \\
.0\end{array}$ & $\begin{array}{l}1382 \\
1350 \\
1310\end{array}$ & $\begin{array}{l}30.0 \\
13.3 \\
23.3\end{array}$ & $\begin{array}{l}1585 \\
1544 \\
1483\end{array}$ & $\begin{array}{l}30.0 \\
28.3 \\
16.7\end{array}$ & $\begin{array}{l}1804 \\
1684 \\
1685\end{array}$ & $\begin{array}{l}31.7 \\
33.3 \\
11.7\end{array}$ \\
\hline \multicolumn{11}{|c|}{ Reorganization } \\
\hline & $A-E$ & $\begin{array}{l}1 \\
2 \\
3\end{array}$ & $\begin{array}{l}1149 \\
1119 \\
1072\end{array}$ & $\begin{array}{r}.0 \\
6.7 \\
.0\end{array}$ & $\begin{array}{l}1620 \\
1692 \\
1634\end{array}$ & $\begin{array}{r}13.3 \\
1.7 \\
5.0\end{array}$ & $\begin{array}{l}1919 \\
1983 \\
2083\end{array}$ & $\begin{array}{r}3.3 \\
6.7 \\
.0\end{array}$ & $\begin{array}{l}2230 \\
2322 \\
2359\end{array}$ & $\begin{array}{l}8.3 \\
5.0 \\
5.0\end{array}$ \\
\hline & $\mathrm{K} \dashv$ & $\begin{array}{l}1 \\
2 \\
3\end{array}$ & $\begin{array}{l}1234 \\
1246 \\
1319\end{array}$ & $\begin{array}{r}8.3 \\
8.3 \\
10.0\end{array}$ & $\begin{array}{l}1804 \\
2040 \\
1872\end{array}$ & $\begin{array}{l}10.0 \\
11.7 \\
10.0\end{array}$ & $\begin{array}{l}2238 \\
2310 \\
2298\end{array}$ & $\begin{array}{r}21.7 \\
10.0 \\
8.3\end{array}$ & $\begin{array}{l}2461 \\
2705 \\
2829\end{array}$ & $\begin{array}{r}38.3 \\
13.3 \\
6.7\end{array}$ \\
\hline
\end{tabular}

Note-Mean square of the variables: task $=62,704,624.0$, target set $=13,859,808.0$, intermember distance $=13,248.0$, and number of items $=21,057,978.8$. 
increase both with number of items $[F(3,54)=$ 47.887] and target set $[F(1,18)=66.462]$. The signiticant Task by Number of Items interaction $[\mathrm{F}(3,54)=9.615]$ suggests that not only is the reorganization task more complex than the identification task but that the difference in difficulty increases with size of the presented set. The Target Set by Number of Items interaction was also signiticant $[F(3,54)=14.200]$, the slope of the RT function being greater for targets drawn from the middle of the alphabet. Although not significant as a main effect $(F<1)$, intermember distance was observed to interact with task $[F(2,36)=6.624]$. As seen in the inset in Figure 1, intermember distance tends to have opposite effects in the two tasks. As intermember distance increased, RT decreased in the identification task and increased slightly (although not signiticantly) in the reorganization task. No other interactions were significant.

The RT data were also analyzed according to serial position of the target item in the presented set. No consistent trend was found over set sizes for either identification or reorganization conditions.

The error data are given in Table 1. Considered in relation to the RT data, two patterns are evident. Within each task, errors and RT are seen to be positively correlated, suggesting that both measures are reflecting processing "difficulty." However, a between-task comparison shows a different pattern in that performance in the identification task is both faster and more error prone. This suggests some variety of speed-accuracy tradeoff, although the processing stage implicated in the tradeoff is not indicated by the data. Failures either to respond or to activate the voice key accounted for $2.1 \%$ of the responses. A marked tendency was observed for within-set errors to fall near the correct response in the alphabetic sequence. For example, when five letters were presented in the identification task, on 60 occasions the second letter in the alphabetic sequence was reported, on 16 occasions the third letter was emitted. on 5 occasions the fourth letter was given, and on 2 occasions the fifth letter was reported. This tendency was observed in varying degrees for each set size.

Error rates are seen to vary over a wide range anong conditions. The average error rate for identification subjects was $17.0 \%$, while for reorganization subjects the value was $8.8 \%$. Furthermore, there were wide differences among subjects within conditions. The relation between error rate and $\mathrm{RT}$ performance was examined by separating the 12 subjects in each instruction condition into high vs. low error-rate subgroups. Under the identification instruction, the subgroup error rates were $21.7 \%$ and $12.3 \%$, respectively, while under the reorganization instruction, the comparable values were $13.1 \%$ and
$4.6 \%$. Separate four-factor analyses of variance (high vs. low rates as a between-subject variable and number of presented items, target set, and intermember distance as within-subject variables) were carried out for each instruction. Under the identification instruction, it was found that high-error-rate subjects responded faster than low-error-rate subjects $[F(1.10)=9.145, \mathrm{p}<.025]$ and that the RT increase with number of presented itemis was greater for low-error-rate than for high-error-rate subjects $[F(3.30)=3.102, p<.05]$. No other interactions involving error rate were significant. Under the reorganization instruction, error rate was neither significant as a main effect nor did it interact with any other variable. Hence, although error rate varied from subject to subject and from condition to condition, it appeared to bear no systematic and important relationship to the effects of manipulated independent variables.

The data of this experiment suggest that searching for the letter appearing earliest in a sequence (identification) is handled differently from a task in which the search for the earliest appearing letter is accompanied (or followed) by a search for other letters according to an alphabetical rule (reorganization). This is evidenced by the greater increase in RT with set size observed for the reorganization task, by the observation that intermember distance had different effects on RT in the two tasks, and by the relations observed between error rate and RT between and within tasks. Further evidence for this contention can be seen when two items are in the set. With a two-item set. identification and reorganization tasks appear to be logically the same, in that the act of identifying one member of the pair as appearing earlier in the alphabet would necessarily fix the relative position of the remaining member, thus fulfilling the requirements for the reorganization task. However, the difference in RT seen at larger set sizes is also observed here, suggesting that the two tasks are basically different at the level of process.

The locus of processing in these tasks is not clear. The stimulus set was on display $4 \mathrm{sec}$ and individual RTs seldom exceeded this amount. Hence, the subject could either work directly from the display or encode the set and work from memory. A second experiment was performed, one purpose of which was to determine if effects similar to those obtained in the first study would be observed if the subject was discouraged from performing the task until the display disappeared, thus requiring that he work from memory. The stimuli were displayed for $4 \mathrm{sec}$, but only after termination of the display was the subject told how to process the stimulus set; i.e., whether to identify the letter in the set coming first in the alphabetic sequence, to reorganize the set into an alphabetical set. or to recite the set in left-to-right 
Table 2

Mean Correct RT (in Milliseconds) and Percentage Errors for the Various Conditions in Experiment II

\begin{tabular}{|c|c|c|c|c|c|c|c|c|c|c|c|c|}
\hline \multirow{4}{*}{$\begin{array}{l}\text { Inter- } \\
\text { member } \\
\text { Distance }\end{array}$} & \multicolumn{4}{|c|}{$\begin{array}{l}\text { Recite Task } \\
\text { Set Size }\end{array}$} & \multicolumn{4}{|c|}{$\begin{array}{l}\text { Identify Task } \\
\text { Set Size }\end{array}$} & \multicolumn{4}{|c|}{$\begin{array}{l}\text { Reorganize Task } \\
\text { Set Size }\end{array}$} \\
\hline & \multicolumn{2}{|c|}{2} & \multicolumn{2}{|c|}{4} & \multicolumn{2}{|c|}{2} & \multicolumn{2}{|c|}{4} & \multicolumn{2}{|c|}{2} & \multicolumn{2}{|c|}{4} \\
\hline & & Percentage & & Percentage & & Percentage & & Percentage & & Percentage & & Percentage \\
\hline & RT & Error & RT & Error & RT & Error & RT & Error & RT & Error & RT & Error \\
\hline \multicolumn{13}{|c|}{ Target Set A-E } \\
\hline $\begin{array}{l}1 \\
3 \\
4\end{array}$ & $\begin{array}{l}2024 \\
2038 \\
2025\end{array}$ & $\begin{array}{r}1.7 \\
.0 \\
.0\end{array}$ & $\begin{array}{l}2244 \\
2194 \\
2194\end{array}$ & $\begin{array}{r}1.7 \\
1.7 \\
.0\end{array}$ & $\begin{array}{l}2106 \\
2024 \\
2091\end{array}$ & $\begin{array}{r}5.8 \\
.8 \\
2.5\end{array}$ & $\begin{array}{l}2415 \\
2409 \\
2305\end{array}$ & $\begin{array}{r}10.0 \\
6.7 \\
7.5\end{array}$ & $\begin{array}{l}2100 \\
2194 \\
2203\end{array}$ & $\begin{array}{r}1.7 \\
.0 \\
1.7\end{array}$ & $\begin{array}{l}2597 \\
2853 \\
2779\end{array}$ & $\begin{array}{l}2.5 \\
3.3 \\
3.3\end{array}$ \\
\hline \multicolumn{13}{|c|}{ Target Set F-J } \\
\hline $\begin{array}{l}1 \\
3 \\
4\end{array}$ & $\begin{array}{l}2053 \\
2086 \\
2025\end{array}$ & $\begin{array}{l}.0 \\
.8 \\
.0\end{array}$ & $\begin{array}{l}2310 \\
2197 \\
2217\end{array}$ & $\begin{array}{l}.8 \\
.0 \\
.8\end{array}$ & $\begin{array}{l}2158 \\
2202 \\
2163\end{array}$ & $\begin{array}{l}9.2 \\
6.7 \\
2.5\end{array}$ & $\begin{array}{l}3041 \\
2980 \\
2754\end{array}$ & $\begin{array}{r}18.3 \\
7.5 \\
6.7\end{array}$ & $\begin{array}{l}2214 \\
2196 \\
2213\end{array}$ & $\begin{array}{r}1.7 \\
.0 \\
3.3\end{array}$ & $\begin{array}{l}2846 \\
3130 \\
3251\end{array}$ & $\begin{array}{r}13.3 \\
8.3 \\
8.3\end{array}$ \\
\hline
\end{tabular}

Note-Mean square of the variables: target set $=7,006,144.0$, intermember distance $=83,072.0$, task $=12,550,368.0$, and set size $=49,322,432.0$.

order. Since an entirely different response would be reported under the recite instruction than would occur under the reorganize or identify instructions, a subject was discouraged from engaging in elaborate processing of the stimulus set before the instruction was given concerning what to do with it. A second purpose of the experiment was to determine if the results of the first study would generalize to a different set of experimental conditions, which included changed values for intermember distance and target set, in addition to the change from a between-subject to a within-subject design.

\section{EXPERIMENT II}

\section{Method}

Subjects. The subjects were 24 students at Virginia Polytechnic Institute. 10 of whom were women, who participated in the experiment as part of a course requirement.

Procedure and Stimuli. On each trial, a randomly ordered set of letters was displayed by a Kodak Carousel projector (Model $760 \mathrm{H}$ ) for $4 \mathrm{sec}$. The stimulus set was followed by a slide containing one of three instruction words: identify, organize, or memorize. If "identify" was displayed, the subject reported the letter in the set coming first in the alphabet. If "organize" was shown, the subject reorganized the presented set for output in alphabetic sequence. When "memorize" was shown, the subject reported the letters in left-to-right order. These three instruction words were selected to roughly equate reading time; however, for continuity in reporting. the conditions will be referred to, respectively, as identify, reorganize, and recite. The offset of the stimulus slide triggered a timer (Hunter Kockounter Model 120C), which stopped when the subject's vocal response activated a voice key (Gerbrands Model 800). Hence, the slide change time (approximately $900 \mathrm{msec}$ ) is included in the RT.

Either two or four letters were presented on each trial; the targets were drawn from the set A, B, C, D, E or the set F, G, H, I, J. The letters in the set were adjacent in the alphabet, spaced two letters apart, or spaced three letters apart in the alphabet. A total of 180 test trials were given, with stimuli constructed according to these rules. The resulting 36 kinds of trials, i.e., 2 set sizes by 3 intermember distances by 2 target sets by 3 instructions, were randomly intermixed and equally represented. Nine practice trials were given with stimuli which were two or four letters in length but which did not conform to the constraints on intermember distance and position of the target letter in the alphabet. A similarly constructed set of nine trials, which were not scored, was scattered among test trials to deter the subject from learning how the test stimuli were constructed. The set of test (and distractor) trials was broken into three blocks of 63 trials each. The order of blocks of trials was counterbalanced over subjects. A brief rest was given between trial blocks. Subjects were assigned to conditions according to a predetermined random order.

\section{Results}

Mean RTs were computed for correct responses for each subject under each condition. As in Experiment I, a response was counted correct if the (first) spoken letter was the correct letter. In order to facilitate comparisons within and between tasks, the data were analyzed separately for each task by means of a four-way analysis of variance (Order of Trial Blocks by Set Size by Intermember Distance by Target Set) and over the three tasks by means of a five-way analysis of variance (Order of Trial Blocks by Set Size by Intermember Distance by Target Set by Task). Interest in the latter analysis centers on the interactions of task with the other major variables. As each of the principal findings is presented, reference is made to the results of both the within-task analysis and the between-task analysis. In each analysis, order of trial blocks was neither significant as a main effect nor produced an important interaction with any other variable and will not be further discussed.

The complete data are given in Table 2. Mean squares for each main effect are given at the bottom of the table. The data, pooled over intermember distance, are displayed separately for each task in the first three panels of Figure 2. The fourth panel shows the effect of intermember distance as a function of task. The within-task analyses showed that RT 


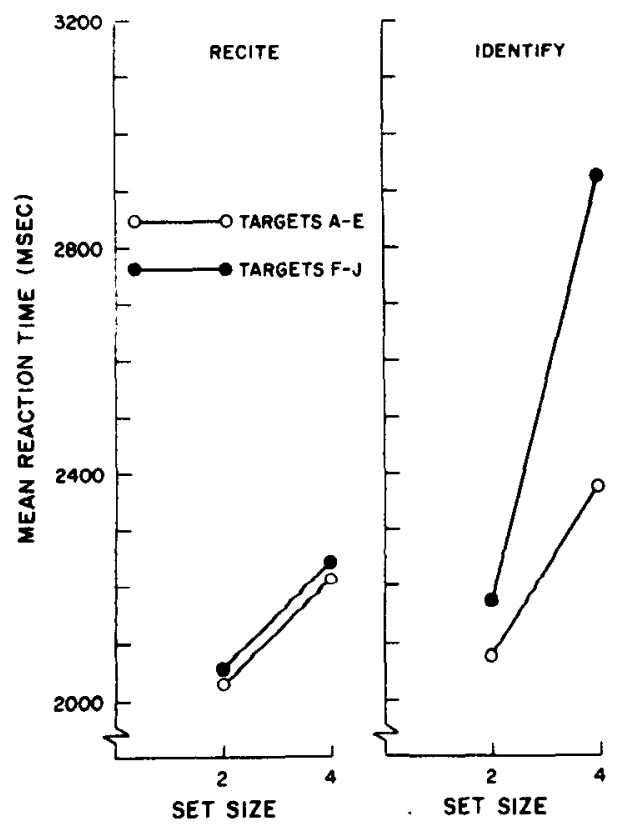

increased with set size in each task $[F(1,18) \geqslant 43.731]$. This $F$ and those reported subsequently have $p$ values ranging from $p<.0005$ to .05 . The between-task analysis showed that the slope of the RT function increased with task difficulty $[F(2,36)=22.031]$. Reaction time was longer for items from the target set $F-J$ than from the set A-E in each task [for recite, $F(1,18)=8.325$; for identify, $F(1,18)=44.550$; for reorganize, $F(1.18)=12.274]$, the effect being greater $[\mathrm{F}(2.36)=19.491]$ under identify and reorganize than under recite instructions. As is seen in the rightmost panel of Figure 2, intermember distance had effects differing according to task $[F(4,72)=12.921]$. Under recite and identify tasks, RT decreased with intermember distance $[F(2,36)=$ 4.274 and $F(2,36)=4.578$, respectively], but increased under the reorganize task $[F(2,36)=$ $11.745]$.

Under each task, the slope of the RT function was affected by intermember distance [for recite, $F(2,36)$ $=3.810 ;$ for identify, $F(2,36)=4.188 ;$ for reorganize, $F(2,36)=3.301$. The way in which intermember distance affected slope again varied according to task $[F(4,72)=5.221]$. The nature of the effect is seen in Table 2; slopes tended to decrease with intermember distance under recite and identify tasks and to increase under the reorganize task. The slope of the RT function varied with target set for identify and reorganize tasks $[F(1,18) \geqslant 11.658]$ but not for the recite task $(F<1)$. The slope effect was reliably different over instructions $[F(2,36)=$ 16.855].

An examination of comparable data points in Figures 1 and 2 shows that the relative vertical displacements of the functions for identification and reorganization conditions decreased from Experiment I to Experiment II. For example, in

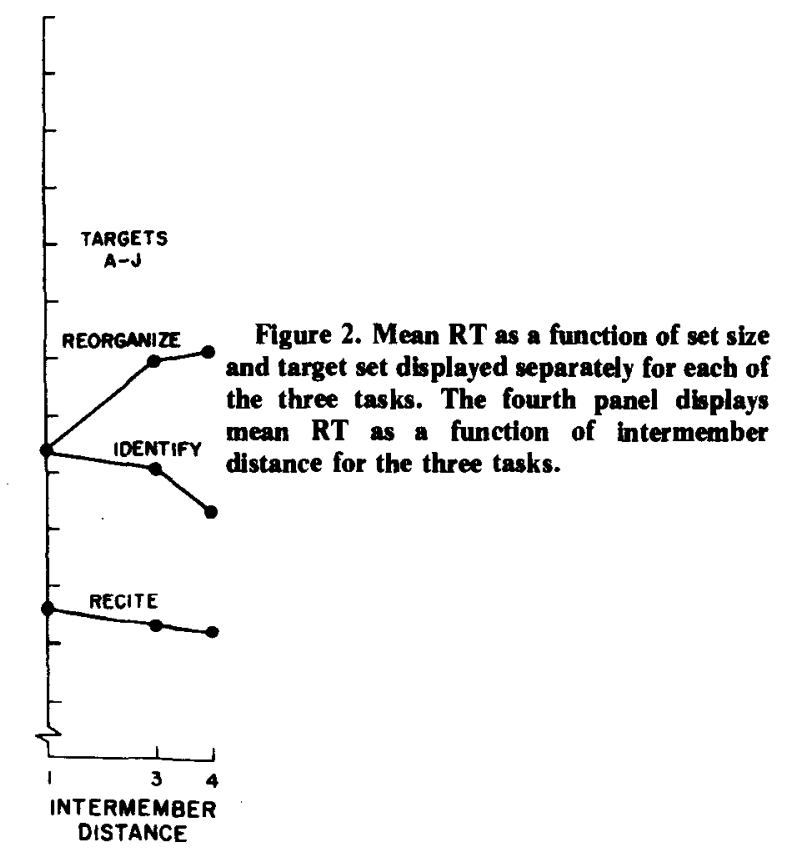

Experiment I, RT for Target Set A-E at Set Size 2 and Intermember Distance 1 was $235 \mathrm{msec}$ faster for identification than for reorganization. Under comparable conditions in Experiment II, RT under the reorganization instruction was $6 \mathrm{msec}$ faster than $\mathrm{RT}$ for the identification instruction.

The error data are given in Table 2. Substantially the same pattern of results displayed here was observed in Experiment I. A major difference is that overall error rates in comparable conditions are lower in Experiment II $(3.9 \%$ vs. $6.0 \%)$. Failures either to respond or to activate the voice key accounted for $1.3 \%$ of the responses.

As in the first experiment, error rates were observed to vary among conditions and subjects. The relationship between error rate and $\mathrm{RT}$ performance was studied by separating subjects into three equal size groups based on overall error rate (with averages of $8.1 \%, 2.4 \%$, and $1.1 \%$ errors, respectively) and casting the data into a five-factor analysis of variance (with error rate as a between-subject variable and set size, intermember distance, target set, and task as within-subject variables). The factor of error rate did not produce a significant main effect on RT, nor did it interact with any of the manipulated variables. Hence, as in Experiment I, although error rates varied widely, they bore no systematic and important relationship to variables of interest.

The design of the present study encouraged the subject to work from memory rather than the display in organizing the response. While there is no adequate way of assessing what the subject was doing with the presented stimulus during the $4 \mathrm{sec}$ of its presentation, it seems unlikely that the period was used to process the stimulus in all appropriate ways. If the stimulus set were completely processed to meet the requirements of all three instructions, all that would 
be needed once the stimulus was removed and the instruction given would be to choose the appropriate response ensemble. If this were the case, it is unlikely that variables such as number of presented items, intermember distance, or position of the target item in the alphabet would have any effect in identification and reorganization tasks, since such variables presunably affect stimulus processing time but not response production time, Yet, in view of the findings of Eriksen, Pollack, and Montague (1970), it also seems unlikely that the subject used the stimulus presentation period to simply memorize the set in left-to-right order. Eriksen et al. have shown that naming latency is a function of the number of syllables (and/or letters) in a word if the subject does not know in advance what the word will be but is unaffected by this variable if the subject silently reads the word a few seconds prior to voicing it. These results would lead one to expect no effect of number of presented items in the recite condition of the present experiment if the stimulus exposure period were simply used for memorization. However, all the major variables, including intermember distance and target set as well as set size, had an effect in the recite condition. Further work will be needed before substantive interpretation can be made of the findings obtained for the recite task.

\section{GENERAL DISCUSSION}

While the designs of Experiments I and II were not exactly parallel, the results were in substantial agreement. In both experiments, RT increased as a function of the number of items in the presented set, with the rate of increase being greater for reorganization than for identification. Also, RT was faster for target items drawn from the beginning of the alphabet, while the effect of intermember distance was different for reorganization and identification tasks. No interaction was observed in either experiment between intermember distance and target set. It was found in Experiment II (but not in Experiment I) that the slope of the RT function was affected both by intermember distance and target set for identification and reorganization. It was observed in Experiment $I$ that the functions for the reorganization conditions were displaced above comparable functions for identification conditions. In Experiment II, the difference in displacement was reduced. The reasons for these differences in results between experiments are not clear; they could have arisen because of differences in processing demands (single task vs. multiple-task set), because the range of conditions was different, or for a combination of these (and other) reasons. The relative importance of any of these factors cannot presently be determined.

It was observed in both experiments that error rates varied widely among conditions and subjects. The following observations, however, suggest that there was no important effect of error rate on performance: (a) despite differing error rates between experiments, the pattern of RT results was the same in both studies; (b) in both studies, despite varying error rates among subjects, the same pattern of results was shown among groups divided on the basis of error rate.

A simple model was offered in the introduction as a first approximation to the processes that might underlie performance in the class of tasks under discussion. This model proposed that the response or set of responses generated on a trial was obtained by an iterative process of pairwise comparisons among stimuli in the presented set. The results obtained in the identification conditions of the two experiments are consonant with predictions of this model. As suggested by the model, RT increased with the number of items in the presented set, decreased with intermember distance, and increased with the position of the target item in the alphabet. The failure to find an interaction between intermember distance and position of the target in the alphabet suggests that these two variables affect different processing stages (Sternberg, 1969). In Moyer and Landauer's (1967) terms, it may be that the position of the target item in the alphabet determines the amount of time required to construct internal analogs or representations of the presented set and that comparison time is affected by intermember distance in the sense that that variable determines the relative magnitudes of the representations.

Performance in the reorganization task cannot be explained in terms of the pairwise comparison model. Contrary to the predictions of that model, RT increased with intermember distance in the reorganization task. The major features of the data for the reorganization condition, including the intermember distance effect, can be explained if it is assumed that the stimulus comparison operation involves a same-different judgment rather than a greater than/less than judgment as had been assumed in the identification task. Parkman (1971) proposed one version of a same-different model. The model developed here assumes that the subject first stores the set of presented items and then matches successive letters of the alphabet (starting with A) against the members of the stored presented set. When a match is obtained, the name of the matched letter could either be output directly or held for output until all letters in the presented set had been successfully matched. If letters were named as soon as they were available, the intermember distance variable should either have no effect on RT to the target item, since variations in intermember distance apply only to the letters which follow the target item, or, if discriminability were an important factor here, produce the same effect observed in the identification conditions. If, however, the first item is held until at least one more letter is 
processed. the obtained intermember distance effect would be predicted because the number of comparisons would increase as the alphabetic spacing of presented letters increases. This hypothesis would also predict increasing RT with number of items in the presented set and longer times for items drawn from the middle of the alphabet than for items from the beginning.

The results of the two experiments reported suggest a way of coupling investigations of simple and complex organization tasks. Identification and reorganization tasks are taxonomically related and have displayed some interesting similarities and differences in performance characteristics. The generality of the findings reported here and the validity of the supposed relations between tasks awaits further work.

\section{REFERENCES}

Butler, D. H.. Kamlet, A. S.. \& Monty, R. A. A multipurpose analysis of variance FORTRAN IV computer program. Psuchonomic Monograph Supplements. 1969. 2(16. Whole No. 32). 301-319.
Chase, W. G..\& Calfee. R. C. Modality and similarity effects in short-term recognition memory. Journal of Experimental Psichologi. 1969. 81. 510-514.

Eriksen, C. W., Pollack, M. D., \& Montague, W. E. Implicit speech: Mechanism in perceptual encoding? Joumal of Experimental Psychology. 1970. 84, 502.507.

FaIRBANK. B. A.. JR. Experiments on the temporal aspects of number perception. Dissertation Abstracts International, 1969. 30. 403.

Lovelace. E. A. \& Snodgrass, R. D. Decision times for alphabetic order of letter pairs. Joumal of Experimental Psychology. 1971. 88. 258-264.

Moyer. R. S.. \& LANDauer. T. K. Time required for judgments of numerical inequality. Nature. 1967, 215. 1519-1520.

Parkman. J. M. Temporal aspects of digit and letter inequality judgments. Joumal of Experimental Psychology. 1971. 91. $191-205$.

Sternberg, S. High-speed scanning in human memory. Science. 1966, 153, 652-654.

Sternberg. S. The discovery of processing stages: Extensions of Donder's method. Acta Psychologica. 1969, 30. 276-315.

Woodworth. R. S. . \& SChlos Berg. H. Experimental psychology. New York: Holt. 1954.

(Received for publication October 25, 1974; revision received April 24, 1975.) 